\title{
Confronting the Democratic Discourse of Librarianship: A Marxist Analysis
}

\section{Michael McNichol ${ }^{1}$}

${ }^{1}$ School of Library and Information Studies, University of Alberta, Email: mcnichol@ualberta.ca

To Cite:

McNichol, M. (2020). Confronting the democratic discourse of librarianship: A Marxist analysis [Review of the book Confronting the democratic discourse of librarianship: A Marxist analysis by Popowich, S]. Pathfinder: A Canadian Journal for Information Science Students and Early Career Professionals, 1(2), 68-71. https://doi.org/10.29173/pathfinder24

\section{Book Information}

Popowich, S. (2019). Confronting the democratic discourse of librarianship: A Marxist analysis. Sacramento, CA: Library Juice Press, ISBN: 978-1-63400-087-1, 322 pages, \$42.99 CAD.

T he notion that libraries are pivotal to the proper functioning of a democracy is ubiquitous, especially within libraries themselves and within Library and Information Studies programs. It is repeated ad nauseum by library CEOs, trustees, and professors, and has, especially, become prevalent in the current debate regarding objectionable speakers being allowed to use the public library as a platform. For example, Vickery Bowles, CEO of the Toronto Public Library and a central figure in the controversy surrounding Trans* Exclusionary Radical Feminist (TERF) speakers, made this explicit in a statement released on October 19, 2019, in which she wrote: "While [Toronto Public Library] encourages public debate and discussion about differing ideas, we also encourage those with opposing or conflicting viewpoints to respectfully challenge each other's ideas and not the library's democratic mandate to provide space for both" (Bowles, 2019, n.p.). In this formulation, "democracy" cannot be challenged. 
In truth, this idea is rarely actively questioned and the result of this privileging of discourse is that when it is challenged, the alternative position presented seems almost heretical. In Confronting the democratic discourse of librarianship: A Marxist approach, Sam Popowich goes beyond this and offers an alternative model of viewing both our society and libraries, as well as the roles that libraries play in individual and communal life. Providing a necessary antidote to the anodyne of the democratic discourse, Popowich dissects the model of librarianship accepted today, gives insight into the deeper roots of our inherited practices, demolishes prejudices, and issues a provocative call for librarians to re-examine librarianship and its role in the modern world.

The most basic issue Popowich raises is surprisingly simple but powerful nevertheless: the statement that libraries are cornerstones of democracy presumes that we live in a democratic state. But is this a presumption? Do we live in a democracy? Popowich would argue that no, we live, rather, in an "authoritarian state which manages the affairs of capital to the detriment of people's lives and the planet" (Popowich, Two democracies, 2019, n.p.). What we call democracy, Popowich argues, is "a noble lie, serving to support an unjust, unequal, and exploitative state of affairs" (Popowich, 2019, p. 30). In a sense, then, this statement serves to discourage any close reading of the nature of our culture and government that could jeopardize that presumption; it is a mystification of the real or material relations at play and serves to reproduce the conditions under which it arose, namely, Enlightenment Liberalism and capitalism.

Popowich, currently Discovery and Web Services Librarian at the University of Alberta Libraries and a Ph.D. candidate in political science at the University of Birmingham, is well-placed to write this critique. He is also a prolific blogger, as can be seen from the number of times his excellent work on Red Librarian is cited in this review. His research in Marxist theory (particularly Italian Marxism, or autonomist Marxism) and his ongoing interest in "a critique of hegemonic intellectual freedom and the ways in which constituent power might offer an alternative perspective more adequate to the current socio-political context" (Popowich, 2020, n.p.) make him eminently qualified.

Popowich's work falls squarely within the realm of "critlib." Critlib can be vaguely defined as the emergent constellation of writers and thinkers who are active in critical 
librarianship, a group to which Popowich could rightly lay claim as a member. As Popowich himself points out, critlib is less a group than a position (or a series of interrelated positions) that queries how libraries and archives, as institutions, are "implicated in structures of domination organized around class, race, gender, sexuality, disability, etc." (Popowich, Rifts and divisions, 2020, n.p.). In this context, Popowich's use of Marxist analysis is particularly insightful. By focusing on the material realities at the base of our social structures and relations, Popowich avoids the sentimentalities that sometimes take the place of analysis in LIS and to expose the ideas that we take for granted for the contingent ideologies they are. Further, Popowich devotes considerable attention to the ways in which identities intersect, showing how race, gender, and sexuality have been subsumed into capitalist logic to further the goals of capitalism itself, i.e., domination and self-reproduction.

It is tempting to see libraries as existing outside this sphere, to see them as somehow exempt from the demands of a culture based on marketplace transactions and the dominion of capital. This wishful thinking arises, in part, because library workers fail to see themselves as workers as such and instead identify, wrongly, with bourgeois class-consciousness (Popowich, 2019, p. 146), and, in part, because by identifying our work with the perpetuation of democracy, we essentially sacralize it and render it untouchable by the profane hand of labour (cf. Ettarh). In the resulting system, libraries, while not erasing the good work done by many librarians, essentially serve "the reproduction of capitalist ideology and social relations" (Popowich, 2019, p. 123).

Although the situation Popowich describes may seem bleak, it is not entirely damning. The final chapter proposes two strategies that Popowich sees as having potential as methods of resistance to capitalist hegemony. This is not a practical guide, however, and is more of a theoretical discussion of potentially disruptive ways of existing prior to the revolution.

Popowich's work is powerful and is well-argued. It is, however, quite academic and many of the basic concepts require significant explanation. Popowich does not presume that every reader is a master of, for example, Gramsci's conceptualization of hegemony, and therefore devotes significant space to the careful explication of relevant ideas and thinkers. However, this is still a substantial work and requires a certain 
amount of prior critical knowledge to be impactful. This would be an entirely appropriate text for any academic collection and would certainly have a strong impact were it to be taught as part of a critical librarianship course.

Popowich problematizes the linkage between libraries and democracies by foregrounding the ways in which libraries act to reproduce the Enlightenment narrative of classical liberalism and capitalism. Although not every reader will agree with his analysis, or be convinced that capitalism is the enemy, it is, nevertheless, a valuable text that disrupts the hegemony of the democratic discourse of librarianship. In an era in which this discourse is being used as the justification for what Popowich has termed "intellectual freedom absolutism" (Popowich, Two democracies, 2019, n.p.), or the privileging of a concept of neutrality which allows for those with power to actively oppress the already marginalized, this disruption is sorely needed.

None declared.

\section{Conflict of Interest Statement}

\section{References}

Bowles, V. (2019, 15 October). City librarian statement on upcoming third-party room rental event. News releases - Toronto Public Library. https://torontopubliclibrary.typepad.com/news releases/2019/10/city-librarianstatement-on-upcoming-third-party-room-rental-event-.html.

Ettarh, F. (2018). Vocational awe and librarianship: The lies we tell ourselves. In the library with the lead pipe. http://www.inthelibrarywiththeleadpipe.org/2018/vocational-awe/.

Popowich, S. (2019). Confronting the democratic discourse of librarianship: A Marxist analysis. Library Juice Press.

Popowich, S. (2019, 30 October). Two democracies - The library and the multitude. Red Librarian Blog. https://redlibrarian.github.io/article/2019/10/30/twodemocracies.html.

Popowich, S. (2020, 30 January). Change of plans. Red Librarian Blog. https://redlibrarian.github.io/article/2020/01/30/change-of-plans.html.

Popowich, S. (2020, 21 February). Rifts and divisions. Red Librarian Blog. 
MCNICHOL

https://redlibrarian.github.io/article/2020/02/21/rifts-and-divisions.html 